\title{
GIORDANO BRUNO E A CRISE RELIGIOSA DA SEGUNDA METADE DO SÉCULO XVI
}

\author{
Ideusa Celestino Lopes ${ }^{1}$
}

\begin{abstract}
Resumo: Neste artigo abordamos a crise religiosa que assolou a Europa no século XVI, iniciada com Martinho Lutero (1483-1546) quando tornou pública a sua insatisfação em 1517, contra vários procedimentos da Igreja Católica Apostólica Romana, em particular o tema das indulgências. O movimento denominado Contrarreforma ou Reforma Católica foi uma reação à disseminação dessas ideias, teve como auge a realização do Concílio de Trento realizado em 1545. Teremos como referência para esse estudo a compreensão elaborada por Giordano Bruno (1548-1600) exposta na obra Spaccio de la bestia trionfante, 2007, publicada em Londres em 1584. A referida obra trata especificamente da crise dos valores morais advinda da cisão dos cristãos em católicos e protestantes. A moral, segundo Bruno é o campo de discussão dos vícios e virtudes, considerados por ele como os primeiros princípios da moral e a religião é considerada como fomentadora da manutenção do convívio social. Para Bruno a sociedade do século XVI não tinha uma religião que desempenhasse este papel, pois se encontrava esfacelada, já que cada grupo defendia uma religião e uma interpretação particular das sagradas escrituras e, porque não dizer, de Deus. A questão principal que permeia a nossa investigação é: o que leva Bruno a criticar seja os católicos, seja os protestantes; o que nos levou a uma outra indagação: ao criticar ambas, Bruno propõe uma terceira via, um outro sistema religioso? Concluímos que a religião, para Bruno, deve ser considerada como um aglutinador social, um instrumento político a ser usado pelos governantes para manter a ordem entre os seus súditos. Os protestantes e os católicos, ao disputarem a posição de verdadeiros intérpretes da divindade, dos sacramentos e das sagradas escrituras, contribuíram para estabelecer a discórdia entre os fiéis, não cumprindo, assim, o seu papel de mantenedora da paz entre os diferentes grupos sociais. Uma possível saída da crise, anunciada no Spaccio, entendemos que está relacionada a incorporação da religião pelo poder político, ou seja, pelo Estado.
\end{abstract}

Palavras-chave: Crise religiosa, Reforma, Crítica.

Abstract: In this article we address the religious crisis that inflicted Europe in the 16th century, initiated by Martin Luther (1483-1546) when he public disclosed his insatisfactions in 1571 against several procedures of the Roman Catholic Church, especially regarding the indulgences. The movement called Counter-Reformation or Catholic Reformation was a reaction to the dissemination of these ideas and had its peak by the time the Council of Trent took place, in 1545. As references to this study there will be used the comprehensions exposed by Giordano Bruno (1548-1600) in the work Spaccio de la bestia trionfante, 2007, published in London in 1584. This work deals specifically with the moral crisis arising from the division of Christians between Catholics and Protestants. The moral according to Bruno is a field of discussion

\footnotetext{
${ }^{1}$ Professora Adjunta do Curso de Filosofia da Universidade Estadual Vale do Acaraú - UVA. Doutora em Filosofia pelo Programa Integrado de Doutorado em Filosofia UFRN-UFPB-UFPE.
} 
regarding vices and virtues, considered by him as the first principles of the moral, and the religion is seen as the stimulator of the socializing experience. To Bruno the 17th century society didn't had a religion that played this part, since it was disintegrated, each group defending a particular interpretation of the sacred scriptures and, in a sense, of God itself. The main question that permeates our investigation is: what led Bruno to criticize either Catholics and Protestants; which bring us to a another search: by criticizing both did Bruno proposes a third way, an alternative religious system? We gather that to Bruno the religion must be considered as a unifying social element, a political instrument to be used by the ones in power to keep the order among their subjects. Protestants and Catholics by disputing the position of true interpreters of the deity, sacraments and sacred scriptures, contributed to establish the quarrel between the believers, unfulfilling its role as keepers of the peace between different social groups. A possible solution for this crisis, proclaimed in Spaccio, is in our understanding related to the annexation of the religion by the political power, the State.

Keywords: Religious crisis, Reformation, Critic.

A Itália da segunda metade do século XVI não era um lugar seguro para os intelectuais que defendiam a liberdade de expressão. Essa tensão se consolidou principalmente a partir do surgimento do movimento conhecido como Reforma Protestante, que se iniciou no começo desse mesmo século, tendo como marco 1517 , quando Martinho Lutero (1483-1546) tornou pública as suas 95 teses, fixadas na porta da Igreja do Castelo de Wittenberg, que colocava em cheque várias condutas adotadas pela Igreja Católica Apostólica Romana, em particular o tema das indulgências. As ideias de Lutero não ficaram restritas a Alemanha, mas se espalharam rapidamente pela Europa. O movimento denominado Contrarreforma ou Reforma Católica foi uma reação à disseminação dessas ideias, teve como auge a realização do Concílio de Trento realizado em 1545. Entre as medidas tomadas nesse Concílio, que são consideras como uma resposta aos reformistas, podemos elencar a retomada do Tribunal do Santo Ofício e a criação do Index Librorum Prohibitorum.

Em 1559 saiu a primeira lista dos livros considerados proibidos pela Igreja Católica, no entanto, não visava tanto os autores recentes mas principalmente o pensamento de autores como Maquiavel, Erasmo de Roterdam, Boccaccio, entre outros. Maquiavel por exemplo não é um pensador que está diretamente ligado aos reformados, mas mesmo assim é incluído na lista. Nesse sentido, a ação repressiva se estendia a todos que colocavam em discussão, direta ou indiretamente, a unidade do catolicismo.

Diante desse quadro conflituoso que se instaurou na segunda metade do século XVI, consideramos Giordano Bruno (1548-1600) como um exemplo de intelectual que

\begin{tabular}{|l|l|l|l|l|}
\hline Qevista Dialectus & Ano 2 & n. 4 & Janeiro-Junho 2014 & p. 13-27 \\
\hline
\end{tabular}


foi formado nessa cisão entre católicos e protestantes. Bruno foi ordenado frade dominicano em 1573, mas três anos depois deixa a ordem religiosa e a Itália, apesar de suas razões não serem originariamente de ordem ideológico-religiosa. Ao deixar a Itália faz uma longa peregrinação por diversos países entre eles a França e a Inglaterra. Estas são nações que conviviam com a diversidade religiosa, pois na França o rei era católico mas o reino era formado tanto por súditos católicos como reformados. Na Inglaterra, a rainha era reformada mas havia o mesmo ambiente misto de súditos. Esse ambiente ambíguo, em que não havia uma predominância de uma posição religiosa em detrimento de outra, mas uma certa correlação de forças, e de certa forma permitia uma "convivência" entre posições diferentes, que Bruno publicou entre os anos de 1581 e 1591 o conjunto das suas obras ${ }^{2}$.

Apesar de Bruno ter tratado de temas diversos ao longo da sua trajetória, a temática cosmológica é o ponto mais evidenciado pelos estudiosos brunianos que, na maioria das vezes, priorizam a discussão cosmológica em detrimento dos outros temas investigados pelo filósofo de Nola. Isto é compreensivo, já que se trata de um tema ao qual Bruno dedicou a maior parte das suas obras, sendo inclusive, o ponto de partida das suas investigações, estando presente tanto nas obras escritas em italiano como em latim. É possível, também, observar o amadurecimento das suas ideias ao longo do seu trajeto, ao se confrontar as ideias expostas na obra A ceia de Cinzas, publicada em 1582, com o último texto em que tratou do referido tema L'immenso e gli innumerevoli, de 1591. Apesar dessa predominância da temática cosmológica Bruno tratou também da moralidade ou da ética ${ }^{3}$. Na obra Spaccio della bestia trionfante, publicada em $1584^{4}$, o tema central é a moral, entendida como campo de discussão dos vícios e virtudes,

\footnotetext{
${ }^{2}$ Essas informações sobre Bruno podem ser conferidas em RICCI (2000) e em nosso artigo publicado na Revista Reflexões: LOPES, Giordano Bruno - De Nola a Roma (2014).

${ }^{3}$ Giovanni Gentile foi o primeiro estudioso que propôs, quando da edição dos diálogos escritos em italiano de Bruno, entre os anos de 1925/27, uma distinção em duas temáticas, metafísica e moral. La cena, De la causa e De l'infinito compondo o primeiro bloco; Lo Spaccio, La cabala e De gl'eroici furori, o segundo. Badaloni, propõem uma distinção dos diálogos em duas partes, cosmologia e ética, apresentada na obra Giordano Bruno tra Cosmologia ed etica. Apesar de ser aceita pela maioria dos estudiosos, tal distinção não é abordada pelo próprio Bruno, como sendo algo inerente ao conjunto das obras citadas.

${ }^{4}$ A obra foi escrita e publicada na Inglaterra e tem como suposto argumento, apresentada pelo próprio autor, a revolta ocorrida em Nápoles nos anos de 1548 e 1564, entre os convertidos luteranos e a inquisição hispânica. Entretanto, os acontecimentos contemporâneos ao filósofo nolano são as crises religiosas inglesa e francesa. Quando da publicação da referida obra Bruno se encontrava na Inglaterra, deste modo imerso na disputa entre os anglicanos, os puritanos e os católicos e, provavelmente, a par de informações sobre conflitos advindo dos países protestantes. Neste período, a rainha Elisabethe gerenciava fortes conflitos entre os puritanos e as autoridades da igreja de estado, a anglicana. Tanto Elisabethe como Henrique III são dois monarcas exaltados por Bruno. No Spaccio, o rei da França é citado como referência de exemplo da luta contra os extremistas, sejam católicos ou reformistas.
}

\begin{tabular}{|l|l|l|l|l|}
\hline Qevista Dialectus & Ano 2 & n. 4 & Janeiro-Junho 2014 & p. 13-27 \\
\hline
\end{tabular}


considerados por Bruno como os primeiros princípios da moral. Nessa obra Bruno aborda explicitamente a cisão entre os católicos e os protestantes.

O diálogo é divido em três partes e subdividido em dois momentos: um atual, no qual participam a deusa Sofia (mediadora entre os deuses e os homens), Saulino (alter ego de Bruno) e Mercúrio (mensageiro divino). O diálogo entre esses três personagens reconstrói um fato acontecido no mundo celeste, no qual Júpiter convoca uma reunião com todos os deuses para discutir o problema da predominância no céu de certas condutas e vícios que propiciaram uma crise tanto no mundo celeste, como entre os humanos, já que os deuses eram uma referência para as condutas dos homens. Para restabelecer a paz, ele propõe uma reforma na distribuição das constelações e dos seus respectivos representantes, expulsando os que representam os vícios e restabelecendo um espaço de destaque para as virtudes.

O argumento bruniano para a realização da "reforma moral celeste", tem como motivo a prática entre os deuses de uma inversão de valores, haja vista que ao longo de algum tempo os vícios vinham sendo enaltecidos em detrimentos das virtudes. Segundo Bruno, uma sociedade que procede dessa forma estaria comprometendo a convivência social entre os seus membros. A partir dessa constatação, Bruno responsabiliza diretamente os protestantes e os católicos como responsáveis pela guerra de religiões na qual a Europa estava enredada. Segundo Bruno os primeiros desmereciam as virtudes, enquanto os católicos as invertiam.

Na obra Spaccio, o motivo da crise celestial é interpretada como sendo causada ou tendo como consequência o modo como as constelações estavam sendo ocupadas. Elas estavam sendo usadas como moeda de troca, pois os deuses que atualmente as ocupavam não o faziam por mérito, mas por recompensa pelo favor ou serviço prestado $^{5}$. A reforma se constitui no momento em que Júpiter, o pai dos deuses, que também praticou atos dignos de censura, pretendia mudar de postura e, para tanto, propõe uma reunião para discutir as possíveis mudanças que poderiam reestabelecer a ordem no mundo celeste. Assim, Júpiter conclama os deuses, partindo da aceitação que foi o primeiro a cometer graves erros,

\footnotetext{
${ }^{5}$ Júpiter não se exclui da crítica, ele também contribuiu com as suas ações para o atual estado de crise e como pai dos deuses assume a tarefa de refletir sobre a sua e a conduta dos outros deuses, sejam seus filhos ou irmãos. Cito uma passagem para elucidar o tom da censura de Giove: "Aquario perché há quarantacinque stelle apresso il Capricorno? Forse perché salvo la figlia di Venere Facete nel stagno? Perché non altri a gli quali noi dei siamo tanto ubligati, che sono sepolti in terra, ma più tosto costui ch'há fatto un serviggio indegno di tanta ricompensa è stato conduto quel spacio? Perché cossì ha piaciuto a Venere" (BRUNO, 2007(e), p. 218).
}

\begin{tabular}{|l|l|l|l|l|}
\hline Qevista Dialectus & Ano 2 & n. 4 & Janeiro-Junho 2014 & p. 13-27 \\
\hline
\end{tabular}


tenho pecado muito gravemente, e pelo mal exemplo vós apresentei a permissão e faculdade de fazer o mesmo [...] temos prevaricado, fomos perseverantes nos erros [...] Convertemo-nos à justiça, da qual estando nós afastados, estamos afastados de nós mesmos de forma que não somos mais deuses, não somos mais nós mesmos. Retornemos então àquela, se queremos retornar a nos mesmos [...] Força (oh Deuses) tirem do céu essas larvas, estátuas, figuras, furtos, ressentimentos, processos e estórias das nossas avarezas, libidinosidades, ressentimentos, despeitos e ofensas [...] (BRUNO, 2007(e), p. 227-228).

Com efeito, a fim de demonstrar a sua intenção de fazer tais mudanças, Júpiter estabeleceu de imediato novas regras de conduta, entre elas citamos as seguintes: ordena que Vulcano não trabalhe aos domingos ou feriados; restringe as orgias de Baco; $\mathrm{Momo}^{6}$, por ter criticado a postura de alguns deuses foi punido, mas Júpiter o absorve e o restitui ao seu posto, permitindo-lhe que faça crítica quando for necessária sem que, por este motivo, seja perseguido. Cupido deve também restringir as suas ações e apresentar-se de modo composto: vestir-se pelo menos da cintura para baixo. Além disso, determinou também que os deuses não devem ter amantes ou serviçais menores de vinte e cinco anos.

A forma de apresentação do ambiente divino e, em particular, a caracterização das ações do pai dos deuses adquire contornos humanos, negando, dessa forma, a ideia de que o âmbito divino é perfeito, bem como imune a vicissitudes. Bruno apresenta, assim, um mundo divino permeado de vícios, e a reforma proposta por Júpiter teria como objetivo extirpá-los. Júpiter chegou à conclusão de que as condutas dos deuses, ao longo do tempo, contribuíram para que os homens perdessem a estima e o temor que lhes devotavam. Segundo Bruno, os deuses não procuravam a reverência, o temor, o amor, o culto e o respeito dos homens para si mesmos, mas para a convivência pacífica entre os homens, pois os deuses, sendo "eles gloriosíssimos em si, e não podendo-lhe acrescentar glória, tem feito as leis não tanto para receber glória, quanto para comunicar glória aos homens",

Júpiter, ao recordar a vitoriosa "batalha contra os Gigantes", evoca a nobreza dos deuses e a repercussão que tais atos surtiram entre os homens. A bravura dos deuses foi celebrada com a construção de oráculos e altares, mas os homens estavam destruindo e profanando esses ambientes, antes celebrados como sagrados, e elegendo novas divindades. Assim, Júpiter solicita aos deuses que reflitam sobre a necessidade da

\footnotetext{
${ }^{6}$ Momo é associado por Bruno à consciência moral. Uma justificativa seria a associação da divindade à critica, a uma absoluta liberdade de expressão, utilizada pela literatura tanto pelos humanistas como pelos renascentistas.

${ }^{7}$ BRUNO, 2007(e), p. 264: “essi gloriosissimo in sé, e non possendosegli aggionger gloria da fuori, han fatto le leggi non tanto per ricevere gloria, quanto per communicar la gloria a gli uomini”.
}

\begin{tabular}{|l|l|l|l|l|}
\hline Qevista Dialectus & Ano 2 & n. 4 & Janeiro-Junho 2014 & p. 13-27 \\
\hline
\end{tabular}


referida reforma e, no intervalo de três dias, devem decidir se ela será feita ou não. Uma vez manifestando-se favorável à proposta de tal reforma, ela seria apresentada ao Conselho e analisada pelos deuses que fazem parte do mesmo e, caso fosse julgada conveniente e necessária, as mudanças deveriam ser implementadas imediatamente para que o céu pudesse torna-se melhor que antes. Júpiter faz o seguinte apelo:

\begin{abstract}
se assim (oh Deuses) purificaremos a nossa morada, se assim tornaremos novo o nosso céu, novas serão as constelações e influxos, novas as impressões, novas fortunas; por que deste mundo superior depende o todo, e efeitos contrários são dependentes de causas contrárias (BRUNO, 2007(e), p. 229).
\end{abstract}

A reforma dos deuses se ocupa especificamente em distinguir o que é vício do que é virtude. O objetivo consistiria em avaliar quem estava ocupando as constelações, em que circunstâncias estas foram ocupadas, e quem as estivessem ocupando indevidamente deveria ser deslocado para outro lugar, sendo as mesmas destinadas a uma outra divindade que as merecesse. Desse modo, o dia considerado como o da vitória dos deuses contra os titãs, passaria a ser concebido como o dia em que os deuses venceram a si mesmos, o dia em que o céu foi limpo dos seus vícios e deu-se o retorno da justiça.

Num primeiro momento, a obra Spaccio pode ser considerada como uma contundente crítica aos protestantes ${ }^{8}$, pois várias são as referências negativas dirigidas a tais indivíduos ao longo da exposição. O texto os descreve da seguinte forma:

seita de pedantes, que sem fazer o bem em conformidade à lei divina e natural, se estimam e querem ser estimados religiosos agradecido aos Deuses, e dizem que o fazer bem é bom, fazer o mau é mau: mas não é pelo bem que se faça, ou pelo mal que se faça, nos tornamos dignos e agradecidos aos Deuses; mas por esperar e acreditar de acordo com a catequese deles ${ }^{9}$.

Entretanto, o conteúdo da obra não pode ser entendido como um ataque dirigido exclusivamente aos protestantes, apesar de o tom mais áspero lhes ser direcionado.

\footnotetext{
${ }^{8}$ Bruno dedicou a referida obra ao inglês Philip Sidney. Apesar da aproximação intelectual com Sidney, protestante, Bruno não era partidário da linha política que o inglês defendia, mas compartilhava dos seus interesses literários, pois era um admirador da literatura italiana, um crítico da eloquência artificial, do ciceronismo e, acima de tudo, um poeta. Philip Sidney, defensor da causa uguinote, foi um dos sobreviventes do massacre de San Bartolomeu, em 1572, ocorrido em Paris. Na Inglaterra, ele apoiava os puritanos e era contrário à aproximação da rainha com o rei da França e ao possível casamento com d'Alençon. Em 1583, casa-se com a filha de Walsingham, puritano, primeiro secretário da rainha. Sidney tinha uma forte influência na vida literária londrina juntamente com Leicester, que era "cancelliere" da Universidade de Oxford. (Cf. RICCI, 2002, p. 224-262).

${ }^{9}$ BRUNO, 2007(e), p. 237-238: "setta de pedanti, che senza ben fare scondo la legge divina e naturale, si stimano e vogliono essere stimati religiosi grati a'Dei, e dicono che il far bene è bene, il far male è male: ma non per ben che si faccia, o mal che non si faccia, si viene ad essere degno e grato a'Dei; ma per sperare e credere secondo il catechismo loro".
} 
Nesse sentido, a postura de anti-reformista não significou, necessariamente, uma defesa do catolicismo.

De acordo com o nolano, o cristianismo é o responsável pelo rompimento da relação entre o mundo divino e o humano, ao instituir a ideia de uma divindade separada do mundo humano. De um modo geral, tal rompimento representou para a humanidade o surgimento de um período de trevas ${ }^{10}$. Eis a origem da crise e de toda a escuridão e ignorância que assolavam a sociedade do seu tempo. É a mesma escuridão que possibilitou o modo equivocado de compreender o mundo físico: a cosmologia do universo finito ${ }^{11}$.

Bruno descreve no século XVI um universo completamente estranho ao que era aceito correntemente ${ }^{12}$. Ao defender a infinitude do universo, ele, paradoxalmente, insere o planeta Terra e os seus habitantes num universo indiferenciado, pois se outros planetas são habitados, nos não seriamos mais os únicos seres no universo. Além disso, a divindade, que era concebida como estando fora do mundo finito, passa a ser entendida como estando em todas as partes, sejam estas grandes ou ínfimas. Essa é uma característica fundamental da cosmologia bruniana: a ideia de homogeneidade. Num universo infinito, povoado de inumeráveis mundos, não há lugar para a distinção de um mundo superior ou inferior ao outro. A homogeneidade do espaço desqualificaria a distinção entre terra e céu e também o significado do espaço celeste como morada da divindade. Bruno reduz a distância entre o mundo humano e o divino, entre um aqui e um ali. Ao negar que existia um "fora do mundo", ele inviabiliza a existência física do paraíso, lugar destinado a compensar quem levou uma vida regrada. Ora, a cristandade defende a ideia de um refúgio post mortem, para o qual a alma é direcionada em sua

\footnotetext{
${ }^{10}$ Luz e sombra podem ser entendidas no pensamento bruniano como uma relação entre vício e virtude, respectivamente; quando um deles influencia o pensamento humano estamos na luz ou na escuridão. Para Bruno, o seu tempo, é um tempo de escuridão, de trevas.

${ }^{11}$ Para Bruno, o cosmo aristotélico é o "primo inconveniente che ne ha generati et è per generarne tanti altri innumerabili" (BRUNO, 2007(b), p. 544), mas somente ganha força quando os teólogos cristãos se apropriam deste discurso e usam o que lhes interessam.

${ }^{12}$ A temática da pluralidade de mundos, por exemplo, não foi um tema exclusivo do século XVI, pois nos séculos XIII e XIV, entre os teólogos, houve um intenso debate, mesmo que meramente hipotético, sobre uma possível pluralidade ou infinidade dos mundos. Tal debate se movimentava num ambiente que procurava conciliar a teoria aristotélica da unicidade do mundo com a cristã, apoiada na onipotência divina. No De caelo, os argumentos a favor da unicidade do mundo estão no livro I capítulo 8 e 9 . E na Fisica livro 8, capítulos sete e nove. O intuito era sempre o de adequar as teses aristotélicas aos princípios da teologia, recurso nem sempre adequado para salvar a convivência entre essas duas instâncias, pois, ao defender a existência de outros mundos, a teologia colocava o problema da comunicação entres os diversos mundos. Um dos postulados da tese geocêntrica é a ideia de centro, existindo outros mundos necessariamente deveria haver outros centros. Mesmo que fossem iguais, tal solução invalidava o sistema aristotélico no tocante à justificativa do movimento perfeito e do lugar natural dos elementos, que se apoiava no axioma de um centro fixo e único.
}

\begin{tabular}{|l|l|l|l|l|}
\hline Qevista Dialectus & Ano 2 & n. 4 & Janeiro-Junho 2014 & p. 13-27 \\
\hline
\end{tabular}


existência espiritual, e Bruno entende isso como um retorno da matéria. Ademais, como o todo está em constante movimento, a matéria não se perde, mas retorna ao mundo.

A nova concepção de mundo tem também como objetivo construir um mundo mais justo, mais igualitário. As virtudes devem ser as condutoras desta reforma, de modo que as diferenças e os méritos individuais não deveriam ser desprezados. $\mathrm{O}$ homem, para Bruno, não é predestinado e o seu caminho é construído por ele mesmo, isto é, trata-se de uma conquista pessoal. Segundo o nolano, os homens deveriam estar atentos à sua existência atual, pois o retorno é certo. A morte é vista não como uma passagem para um outro mundo, mas como um ato implícito à vida, como um evento necessário. No entanto, as condições de tal retorno seriam condicionadas pelos atos precedentes. Na roda da fortuna, não há garantia que na próxima vida tudo retorne a ser o que era. Todavia, para ele, pode-se, através de boas ações e de boa vontade nesta vida, preparar um bom retorno para a próxima ${ }^{13}$. Enquanto as religiões falam de um post mortem e de uma imagem que remete a um lugar separado do mundo terreno, Bruno faz referência à necessidade de se cobrar ações no mundo, pois o retorno se daria em outras condições, se melhores ou piores do que a atual, isto dependeria das ações cometidas, ou seja, "por isso no mundo cada um seja premiado e castigado de acordo com a medida dos merecimentos e delitos" $" 14$.

Desse modo, a reforma celeste apresentada no Spaccio pode ser compreendida como um momento de reflexão e um anúncio de atitudes a partir das quais se espera que a sociedade possa encontrar a luz. Mas essa luz, não significou para Bruno, uma adesão à reforma protestante, pois, ele dirige a sua crítica seja aos católicos, seja aos reformados. Todavia, o que sobressai no texto é uma veemente crítica direcionada aos antigos vícios e aos erros contumazes, aos quais os católicos e os protestantes não estariam imunes. Desse modo, Bruno está propondo uma reforma que leve em conta tanto os vícios e erros dos católicos, como os dos protestantes. Nesse sentido, a discussão bruniana de uma reforma celeste pode ser compreendida como a construção de um projeto de paz que possa superar a crise política-religiosa na qual a Europa estava imersa.

O ponto de partida no qual Bruno se apoia para discutir uma reforma moral tem como referência a ideia da religião como fomentadora da manutenção do convívio

\footnotetext{
${ }^{13}$ Como, para Bruno, não há distinção entre o mundo celeste e o humano, a alma e a matéria estão em permanente mutação. Assim, não existe a ideia de um fim, mas de um constante movimento.

${ }^{14}$ BRUNO, 2007(e), p. 242: "per cui nel mondo ogniuno vegna premiato e castigato secondo la misura de gli meritit e delitti".
}

\begin{tabular}{|l|l|l|l|l|}
\hline Qevista Dialectus & Ano 2 & n. 4 & Janeiro-Junho 2014 & p. 13-27 \\
\hline
\end{tabular}


social. A justificativa para tal empresa se apoia nos exemplos de duas civilizações, a egípcia e a romana, que teriam tido as suas trajetórias marcadas pelo forte sentimento religioso que as sustentavam. Na avaliação do nolano, a sociedade do século XVI não tinha uma religião que desempenhasse este papel, pois se encontrava esfacelada, já que cada grupo defendia uma religião e uma interpretação particular das sagradas escrituras e, porque não dizer, de Deus.

O resgate do culto egípcio ${ }^{15}$ presente no pensamento do filósofo nolano tem como referencial a relação que se estabelecia entre a divindade e a natureza, um elo sem mediação. Havia uma interação imediata entre a natureza, o homem e a divindade. Essa interação, segundo Bruno, foi interrompida pelas religiões hebraica e cristã, que condenaram os ritos considerados pagãos. Para o nolano, o culto pagão não era mera fantasia ou devaneio de uma cultura insana. Ao contrário, os seus ritos eram profundos e autênticos, de modo que alcançavam a divindade diretamente ${ }^{16}$. Para Bruno, os egípcios

vendo um homem no qual era excelente a majestade, a justiça, a magnanimidade, entendiam que nele estava deus, magnânimo, justo e benigno [...] De forma que neste homem não vem celebrada outra coisa que o nome e representação da divindade, que com o nascimento daqueles veio a comunicar-se com os homens, e com a morte eles entendiam ter cumprido o curso da sua obra, $[\ldots]$ nunca foram adorados crocodilos, galos, cebolas e beterrabas; mas os Deuses e a divindade nos crocodilos, nos galos e em outros: os quais em certos tempos lugares, sucessivamente encontrou-se, encontra-se e se encontrará em diversos sujeitos mortais ${ }^{17}$.

Assim, eles poderiam até adorar outros homens, mas, em particular, era reverenciada a divindade que coabitavam neles. Bruno critica a relação entre a religião cristã e os seus símbolos, em particular a adoração de relíquias. Na obra Spaccio, ele satiriza a adoração ao rabo do jumento que conduziu Jesus do Monte das Oliveiras até Jerusalém, já que o mesmo era adorado e guardado como tesouro pelo povo cristão:

\footnotetext{
${ }^{15}$ Segundo Ingegno, a influência no pensamento bruniano da religião egípcia deve ser entendida no âmbito da sua polêmica anti-cristã, ao apresentar a egípcia como exemplo de religiosidade que mantém uma relação da divindade com todos os seres que compõe a natureza mantida através do rito mágico. (Cf. INGEGNO, 1967, p. 157-174). Mas, ao mesmo tempo que Bruno é um copernicano, também é possível afirmar a influencia do hermetismo no seu pensamento; o problemático é quando se apega a um aspecto e nega o outro, não dimensionando a influência no desenvolvimento da sua obra. A interpretação de Yates sobre o cosmo bruniano é tão centrada no hermetismo que parece inexistente a relação do mesmo com o copernicanismo.

${ }^{16}$ Para aprofundar essa questão, ver o texto BRUNO, 2007(e), p. 357.

${ }^{17}$ BRUNO, 2007(e), p. 359, "vedendo un uomo in cui era eccellente la maestà, la giustizia, la magnanimità, intendevano in lui esser dio magnanimo, giusto e benigno [...] Di maniera che di questo e quell'uomo non viene celebrato altro che il nome e representazion della divinità, che con la natività di quelli era venuta a comunicarsi a gli uomini, e con la morte loro s'intendeva aver compito il corso de l'opra sua, o ritornata in cielo [...] mai furono adorati crocodilli, galli, cipolle e rape; ma gli Dei e la divinità in crocodilli, galli et altri: la quali in certi tempi e tempi, luoghi e luoghi, sucessivamente et insieme insieme, si trovò, si trova e si trovarà in diversi suggetti quantumque siano mortali”.
}

\begin{tabular}{|l|l|l|l|l|}
\hline Qevista Dialectus & Ano 2 & n. 4 & Janeiro-Junho 2014 & p. 13-27 \\
\hline
\end{tabular}


"Não toquem, beijem: esta é santa relíquia daquela bendita asna que foi feita digna de carregar o nosso Deus do Monte Oliveto a Ierosolina. Adorá-la, beijá-la, oferecei-lhe esmola" ${ }^{18}$. Bruno expressa a sua ironia ao afirmar que, se um pedaço de um animal morto é tão adorado, então o animal inteiro e vivo deveria ser ainda mais glorificado. A religião egípcia usava os animais e outros entes da natureza em seus cultos, como sendo uma manifestação do divino. Desse modo, Bruno critica os cristãos que divinizam pessoas ou certos objetos, desmerecendo o divino que existe em cada parte da natureza e glorificando os que foram supostamente eleitos por eles, mas, na maioria das vezes, podem ter o espírito mais brutalizado que o mais feroz dos animais ${ }^{19}$. Conceber a natureza e a divindade de modo estanque é, segundo o nolano, próprio de uma cultura que vive nas trevas, que perdeu a noção do verdadeiro divino e inverteu os valores. Os animais que são partes do divino passam a ser desprezados por serem animais, enquanto são idolatrados alguns homens e os objetos tocados por eles. Na última parte do terceiro diálogo do Spaccio, Bruno critica a religião cristã e os seus dogmas, seja ela reformada ou não, acusando-a de ter condenado uma sabedoria precedente, invertendo os valores:

fazendo-lhe acreditar que o branco é preto, que o intelecto humano, onde lhe parece melhor ver, é uma cegueira; e aquilo que em conformidade com a razão parece excelente, bom e ótimo: é vil, malvado e extremamente mau; que a natureza é uma prostituta meretriz, que a lei natural é uma malvadeza; que a natureza e divindade não podem concorrer para um mesmo bom fim, e que a justiça de um é subordinada à justiça da outra, mas são coisas contrárias, como a obscuridade e a luz ${ }^{20}$.

A desagregação que permeia a sociedade do seu tempo é, para Bruno, o ápice da realização da profecia de Trimegisto ${ }^{21}$, um profeta egípcio que descreveu um futuro nefasto para a humanidade. Bruno cita o seguinte trecho da profecia no Spaccio:

A escuridão total se proporá à luz, a morte será julgada mais útil que a vida, ninguém levantará os olhos ao céu, o religioso será estimado não saudável, o ímpio será julgado prudente, o furioso forte, o péssimo bom. E acreditem em mim que ainda será determinada/fixada pena capital àquele que se aplicará à religião da mente: por que se encontrarão novas justiças, novas leis, nada se encontrará de santo, nada de religioso; não se ouvirá coisa digna de céu ou dos deuses do céu. Só permanecerão anjos perniciosos, os quais misturados

\footnotetext{
${ }^{18}$ BRUNO, 2007(e), p. 370, "Non toccate, baciate: questa è la santa relíquia di quella benedetta asina che fu fatta degna di portar il nostro Dio dal Monte Oliveto a Ierosolima, Adoratela, baciatela, porgeite limosina".

${ }^{19}$ Cf., BRUNO, 2007(e), p. 372.

${ }^{20}$ BRUNO, 2007(e), p. 381, "facendo gli credere que il bianco è nero, che l'intelletto umano, dove li par meglio vedere, è una cecità; e cì̀ che secondo la raggione pare eccelente, buono et ottimo: ̀̀ vile, scelerato er estremamente malo; che la natura è una puttana bagassa, che la legge naturale è una ribaldaria; che la natura e divinà non possono concorrere in uno medesimo buono fine, e che la giustizia de l'uno è subordinata alla giustizia de l'altra, ma son cose contrarie, come le tenebre e la luce".

21 Trimegisto é uma fonte bastante discutida no pensamento bruniano. Frances Yates, por exemplo, propôs uma forte ligação entre Bruno e o hermetismo de Trimegisto, desconsiderando outras possíveis vias interpretativas.
}

\begin{tabular}{|l|l|l|l|l|}
\hline Qevista Dialectus & Ano 2 & n. 4 & Janeiro-Junho 2014 & p. 13-27 \\
\hline
\end{tabular}


com os homens forçarão os humildes à audácia de todo mal, como se fosse justiça, doando matéria a guerras, roubos, enganos, e todas outras coisas contrárias à alma e justiça natural: e esta será a velhice e a desordem e a falta de religião do mundo ${ }^{22}$.

Consideramos que esta é uma das missões do filósofo nolano: evidenciar o rompimento entre lei divina e lei natural e as consequências nefastas de tal rompimento para a humanidade em seu aspecto tanto cosmológico quanto social. Assim, se a cosmologia bruniana é uma restauração da relação intrínseca entre Deus e a natureza, tal preocupação não se limita a tal dimensão, pois ela se expande para as relações humanas, pois o homem também deve se compreender como um ser natural e participante da sua dinâmica e da relação com a divindade.

Entretanto, a religião egípcia e a romana, pertenciam ao passado e não havia eco delas na sociedade atual. Como, para Bruno, a sociedade não pode viver sem religião, qual seria então a saída para a crise que assolava a Europa? Uma possível saída da crise, anunciada no Spaccio, entendemos que está relacionada a incorporação da religião pelo poder político, ou seja, pelo Estado. A figura emblemática para realizar tal fusão seria o rei da França Henrique III. A sociedade, assim conduzida, estaria livre do poder excessivo que a igreja católica assumiu nos últimos tempo e, com isso, seria debelada a crise religiosa entre os católicos e os reformistas.

O Estado ideal bruniano é um Estado forte, fundado na tradição do mito de Hércules. Tal Estado deveria estimular ou desencorajar, promover ou reprimir, determinados comportamentos morais e sociais. Tal proposta se inspira tanto na República de Platão, como na proposta erasmiana, sem esquecer o modelo de sociedade romana tanto exaltada por Maquiavel. O Estado deve ter como missão estimular o exercício das virtudes e do bem comum, sob a tutela da filosofia. Henrique III personifica, no pensamento bruniano, o defensor da paz, mas não de uma paz ingênua e apoiada apenas em belos discursos. Para conquistar e manter um estado de paz, preconiza Bruno, é preciso o uso da força quando necessário, ou ainda de sabedoria para escolher o momento certo de usa-la. É certo que não existe paz com guerra, porém é preciso força militar para mantê-la. Além da força, é necessária também a definição de

\footnotetext{
${ }^{22}$ BRUNO, 2007(e), p. 364, "Le tenebre si proponeranno alla luce, la morte sarà giudicata più utile che la vita, nessuno alzarà gli occhi al cielo, il religioso sarà stimato insano, l'empio sarà giudicato prudente, il furioso forte, il pessimo buono. E credetemi che ancora sarà definita pena capitale a colui che s'applicarà alla religion della mente: perché si trovaranno nove giustizie, nuove leggi, nulla si trovarà di santo, nulla di religioso; non si udirà cosa degna di cielo o di celesti. Soli angeli perniciosi rimarranno, li quali mechiati con gli uomini forzaranno gli miseri all'audacia di ogni male, come fusse gisutizia, donando materia a guerre, rapine, frodi, e tutte altre cose contrarie alla anima e giustizia naturale: e questa sarà la vecchiaia et il disordine e la irreligione del mondo".
}

\begin{tabular}{|l|l|l|l|l|}
\hline Qevista Dialectus & Ano 2 & n. 4 & Janeiro-Junho 2014 & p. 13-27 \\
\hline
\end{tabular}


uma política pacifista. O Estado deve estar em constante vigilância para que a paz conquistada seja mantida. Segundo Bruno, a divisão religiosa iniciada com os protestantes constituiu-se como uma ameaça à unidade política, pois as ações que promovem a civilidade e a sociabilidade são desprezadas por eles. Para ele, os protestantes são usurpadores do patrimônio material, social e político construído pelos católicos $^{23}$. Como a cisão entre católicos e protestantes se apresenta cada vez mais irremediável, Bruno indica o modo como o Estado justo deve tratar as duas tendências religiosas. Os protestantes, segundo o nolano, são naturalmente inimigos do estado e extremistas na defesa dos seus preceitos; os católicos, por sua vez, acreditam no bem comum e no desenvolvimento do estado político. Nesse sentido, que Bruno, ao que parece, faz opção pelos católicos.

O elo entre a reforma celeste e reforma bruniana se evidencia, no nosso modo de ver, quando Bruno introduz no seu texto a discussão sobre dois personagens: Hércules e Perseu. Na reforma celeste, tanto Hércules como Perseu são desalojados das suas constelações em virtude de não serem deuses, mas semi-deuses. Apesar de terem sido destituídos dos lugares que ocupavam, Júpiter defende os dois filhos, exaltando os seus atos heróicos, enquanto estavam entre os humanos, e assim ele os destinam para uma nova missão: retornar à Terra com o intuito de restaurar a paz entre os homens, ou seja, deixar o mundo novamente seguro para a humanidade. A Perseu é dada a incumbência de destruir o monstro, a Medusa, que ameaçava a Europa, personificado por Bruno como sendo os reformadores. Para cumpri-la com o êxito esperado, ele teria o apoio de todos os deuses para essa batalha, inclusive lhe é permitido usar Pégaso.

O Hércules bruniano não é um deus e nem um semi-deus, mas é concebido como um "deus" terrestre ${ }^{24}$, um enviado de Júpiter para conduzir os humanos em seu aperfeiçoamento moral e intelectual, visando fundar uma nova ordem social baseada nos preceitos da "antiga e verdadeira filosofia". Um dos atributos de Hércules, exaltado por

\footnotetext{
${ }^{23}$ A referência para a construção de tal imagem, segundo Ricci, se deve ao fato de Bruno ter presenciado na França o espólio do patrimônio material da igreja católica pelos huguenotes. Essa interpretação é a mais ácida da posição anti-reformista bruniana (cf. RICCI, 2002, p. 244).

${ }^{24}$ Bruno, ao designar Hércules como "deus humano", levantou a questão sobre quem representava Hércules no mundo humano? Existem alguns nomes que são elencados como representando o Hércule bruniano: Henrique III, d'Alençon, irmão de Henrique III, Henrique di Guisa, ou ainda Henrique di Navarra, o futuro rei da França (que terá a missão de defender o catolicismo e frear a expansão do calvinismo). Além dos nomes já elencados, um outro a ser acrescentado é o de Alessandro Farnese (príncipe italiano, duque de Parma e católico) que, lutando pela Espanha de Felipe II, reconquistou o território dos países baixos do domínio calvinista. Tal êxito aumentou a sua fama de estadista, diplomata, político, qualidades estas que o filósofo nolano considerava essenciais para libertar a Europa dos reformadores, contribuindo para o restabelecimento da paz. (Cf. RICCI, 2002, p. 239 et seq.)
}

\begin{tabular}{|l|l|l|l|l|}
\hline Qevista Dialectus & Ano 2 & n. 4 & Janeiro-Junho 2014 & p. 13-27 \\
\hline
\end{tabular}


Bruno, estaria em bem saber administrar a força física, entendida como tática militar, aliada à prudência política ${ }^{25}$.

$\mathrm{Na}$ reforma ocorrida entre os deuses, Perseu e Hércules são apresentados como símbolos da deusa Fadiga, cuja característica é ter disposição e ser trabalhadora, já que todas as suas conquistas foram frutos de muito esforço. Assim, o heroísmo de ambos é fruto das batalhas que travaram, "pelo qual digo se supera toda vigilância, se quebra cada adversa ocasião, se facilita todo caminho e acesso, se adquire todo tesouro" (BRUNO, 2007(e), p. 307).

Entretanto, Bruno, não pode ser descrito como um defensor da tolerância e do respeito pelas diferenças religiosas. Ele defende que o Estado deve ter uma orientação espiritual definida, por isso, não é um defensor de uma convivência entre tendências religiosas que possam ser gerenciadas pelo governante ${ }^{26}$. A convivência pacífica entre orientações religiosas diferentes era um debate que envolvia vários setores da sociedade do seu tempo. Nessa perspectiva, dois pontos eram indispensáveis: a liberdade de culto para todas as religiões e a existência de um Estado totalmente laico. Há, ainda, uma distinção no período renascentista entre lei divina e lei humana ou civil. A primeira refere-se à religião e a segunda às leis que regem a sociedade civil. Bruno segue uma via intermediária ao defender a harmonia entre as duas dimensões, divina e civil, as quais teriam o mesmo objetivo: a paz entre os homens através de regras de conduta que permitam a conservação da sociedade. Para Bruno, as regras de conduta moral foram criadas para favorecer a convivência pacífica entre os homens. A referência é explicita à religião de Estado romana em que os ritos e as cerimônias eram realizados tendo em vista a coesão social e, com isso, visavam desestimular ações nocivas à sociedade ${ }^{27}$.

A sociedade do século XVI era dominada pela concepção do sagrado construída pelos cristãos. Essa dimensão permeava a sociedade em todos os seus âmbitos, seja na dimensão político, social ou científico. Apesar da formação religiosa romana e da convivência com vários expoentes da reforma, sejam eles calvinistas ou luteranos,

\footnotetext{
${ }^{25}$ Essas características são as mesmas apresentadas para descrever Henrique III.

${ }^{26}$ A França e a Inglaterra são exemplos de Estados que tinham, no século XVI, uma religião oficial e procuravam administrar a convivência com orientações espirituais diversas. Essa temática será aprofundada posteriormente por Spinoza (1632-1677) ao defender um Estado laico sustentado através de um pacto social e a liberdade dos cidadãos, mediante a adoção de um credo religioso universal apoiado na liberdade e tolerância, mas orientada pela autoridade espiritual de Cristo, apresentada na obra Tractatus theologico-politicus.

${ }^{27}$ Esta leitura é influenciada pelo pensamento maquiavélico que reforça o culto religioso como intimamente ligado à vida civil. Para um aprofundamento da relação entre Bruno e Maquiavel ver o texto de GRANADA, 2002, p. 343-368.
}

\begin{tabular}{|l|l|l|l|l|}
\hline Qevista Dialectus & Ano 2 & n. 4 & Janeiro-Junho 2014 & p. 13-27 \\
\hline
\end{tabular}


Bruno não defendeu um modelo religioso em detrimento do outro. Ele considerava que ambos tinham a mesma fonte, a mesma concepção de divindade, apesar de suas peculiaridades. A religião, para Bruno, deve ser considerada como um aglutinador social, um instrumento político a ser usado pelos governantes para manter a ordem entre os seus súditos. Os protestantes e os católicos, ao disputarem a posição de verdadeiros intérpretes da divindade, dos sacramentos e das sagradas escrituras, contribuíram para estabelecer a discórdia entre os fiéis, não cumprindo, assim, o seu papel de mantenedora da paz entre os diferentes grupos sociais. Nesse sentido, consideramos que Bruno fomentou uma reforma racional da teologia ao criticar a teologia tradicional que representava Deus antropomorficamente. Com isso, o saber teológico seria perpassado pelo saber filosófico, pelo processo argumentativo e não seria aceito apenas como uma declaração de fé.

\section{Referências Bibliográficas}

BADALONI, Nicola. Tra cosmologia ed etica. Bari-Roma: Società Editrice Barese, 1988.

BRUNO, Giordano. Opere italiane - 2 vols. Torino: UTET Libreria, 2007.

La cena delle ceneri. In: Opere italiane. Torino: UTET Libreria, 2007 (b), p. $425-571.2$ v.

Spaccio della bestia trionfante. In:

Opere italiane. Torino: UTET Libreria, 2007 (e), p. 169 - 402.2 v.

L'immenso e gli innumerevoli. In: . Opere latine di Giordano Bruno. A cura di Carlo Monti. Torino: Unione tipografico-editrice torinese, 1980, p. $415-819$.

GRANADA, M. Angel. Blasphemia vero est facere Deum alium a Deo. In: Del Lessico Intellettuale europeo. Bruniana \& Campanelliana. Pisa - Roma: Fabrizio Serra - editore ,XI, p.151 - 188, 2002.

INGEGNO, Alfonso. Ermetismo e oroscopo delle religioni nello 'Spaccio' bruniano. In: Rinascimento, 7, p. 157-174, 1967.

RICCI, Saverio. Riformazione, Eresia e Scima nello Spacio de la bestia trionfante. In: Bruniana \& Campanelliana. Pisa - Roma: Fabrizio Serra - editore, Supllementi Studi - 3, p. 224-262, 2002.

\begin{tabular}{|l|l|l|l|l|}
\hline Qexista Dialectus & Ano 2 & n. 4 & Janeiro-Junho 2014 & p. 13-27 \\
\hline
\end{tabular}



2000.

Giordano Bruno nell'europa del cinquecento. Roma: Salerno Editrice,

SPINOSA, Baruch de. Tratado Teológico-Político. Trad. Diogo Pires Aurélio. São Paulo: Martins Fontes, 2003. 